\title{
Disturbance in respiratory mechanics in infants with bronchiolitis
}

\author{
J SEIDENBERG, I B MASTERS, I HUDSON, A OLINSKY, P D PHELAN \\ From the Professorial Department of Thoracic Medicine, Royal Children's Hospital, and University Department- \\ of Paediatrics, Melbourne, Australia
}

ABSTRACT The passive flow-volume and partial forced expiratory flow-volume techniques were used to assess pulmonary function in 14 spontaneously breathing infants with acute respiratoryo syncytial virus bronchiolitis. Two additional infants were studied while paralysed and ventilated尺 During the acute stage of the illness there was a significant reduction in forced expiratory flow rates and an increase in respiratory resistance. Although the mean thoracic gas volume for the group was increased, five infants did not compensate for their airways obstruction by hyperinflation Curvilinear passive flow-volume curves were seen in three of the 14 non-ventilated infants and in botto ventilated infants. At follow up three to four months later all passive flow-volume curves were lineares There was a significant reduction in hyperinflation and an increase in forced expiratory flow rates, buto values still differed significantly from those in normal infants.

\section{Introduction}

Acute viral bronchiolitis is the most common serious lower respiratory infection in the first six months of life. The clinical picture is one of small airway obstruction and pulmonary hyperinflation. Pulmonary function tests in the acute phase of the illness confirm the clinical and radiological evidence of airflow obstruction and gas trapping. ${ }^{2}$ Criticism has, however, been levelled at the tests used to assess lung function, suggesting that they may not reflect changes in airway function accurately. ${ }^{34}$

New methods of evaluating lung function in young infants have been developed recently. Total respiratory system compliance and resistance have been measured by the occlusion and passive flow-volume techniques in newborn and older infants ${ }^{56}$ and maximum expiratory flow rates by the partial forced expiratory flow-volume technique. ${ }^{78}$ The two techniques allow measurements to be made without oesophageal balloons, which have major methodological problems in infancy, ${ }^{3}$ and without the complex equipment needed for the rebreathing method for measuring airways resistance, ${ }^{9}$ which is not particularly suitable for ill infants. The passive technique makes

Address for reprint requests: Dr A Olinsky, Professorial Department of Thoracic Medicine, Royal Children's Hospital, Parkville 3052 Victoria, Australia. use of the observation that infants have a Hering Breuer reflex. ${ }^{10}$ After transient occlusion at end ins piration the infant expires passively; the normal plot of expiratory flow against lung volume is a straight line This allows calculation of the resistance and com 0 pliance of the respiratory system without use of invasive techniques.

In the present study we combined the two tech niques to study infants with acute bronchiolitis due tof respiratory syncytial virus during the acute anf recovery phases of the illness. In addition, passive expiration was studied in two paralysed and ventilated infants with bronchiolitis. The aim was to document abnormalities in respiratory mechanics and to obtain insights into mechanisms used by the infants to compensate for the pathological changes.

\section{Methods}

PATIENTS

We studied 16 previously healthy infants admitted to hospital with acute bronchiolitis. The project was approved by the hospital ethics committee and infor med consent obtained from the parents. In most case one parent was present during the examination.

The mean age of the 14 infants studied at about the eighth day of the illness was 20 (range 4-41) weeks They were studied again three to four months later Two infants aged 6 and 8 weeks were studied while paralysed and ventilated. The diagnosis of bron 0 chiolitis was based on the presence of tachypnoea 660 
hyperinflation, wheezing, and widespread crepitations. These were present at the time of the first study, though the spontaneously breathing infants no longer required nursing in a high oxygen environment. All patients had a positive result in the immunofluorescence test for respiratory syncytial virus antigen in the nasopharyngeal secretions. In the follow up study eight babies still had intermittent wheeze but were otherwise well.

\section{INVESTIGATIONS}

The spontaneously breathing infants were studied lying supine with the neck slightly extended in a 40 litre body plethysmograph, after receiving $80 \mathrm{mg} / \mathrm{kg}$ chloral hydrate. A three position slide valve, modified from that originally described by Le Souef $e t$ al, ${ }^{5}$ was fixed to the face with silicone putty. Flow was measured with a Fleisch No 1 pneumotachograph and a Validyne DP 45 pressure transducer. Volume was determined by electronic integration of the flow signal and drift was carefully adjusted. Flow and volume were displayed on a Tektronix 5223 digitising oscilloscope and recorded on tape with a Racal thermionic store $4 \mathrm{D}$ recorder. These signals and pressure were also displayed on a chart recorder (HP 7754A). Mouth pressure was measured via a port between the face mask and slide valve by means of a Hewlett Packard 128 OC pressure transducer. The pressure in the plethysmograph and cuff used for compression were measured with similar transducers.

\section{Respiratory timing}

During spontaneous tidal ventilation the duration of a respiratory cycle (Ttot) and inspiratory time (Ti) were measured from the flow tracings and expressed as Ti/Ttot.

\section{Passive expiratory flow manoeuvre}

The passive compliance (Crs), resistance (Rrs), and time constant (Trs) of the total respiratory system were obtained by the airway occlusion technique. ${ }^{5}$ Brief occlusion at end inspiration was performed with the slide valve between mask and pneumotachograph. The occlusion was released as soon as a plateau of mouth pressure was reached and, in the absence of flow, equalisation of pressure within the respiratory system was assumed. The linear part of the passive expiratory flow-volume (PEFV) curve was extrapolated to the flow and volume axes to calculate $\mathrm{Crs}$, Rrs, and Trs (fig 1). (Compliance (Crs) = extrapolated expired volume (VE)/occlusion mouth pressure $(\mathrm{Pao})$, and resistance $(\mathrm{Rrs})=$ occlusion mouth pressure (Pao)/extrapolated expiratory flow (V்o) at end inspired volume.)

In the two paralysed and ventilated infants the slide valve was attached to the endotracheal tube and

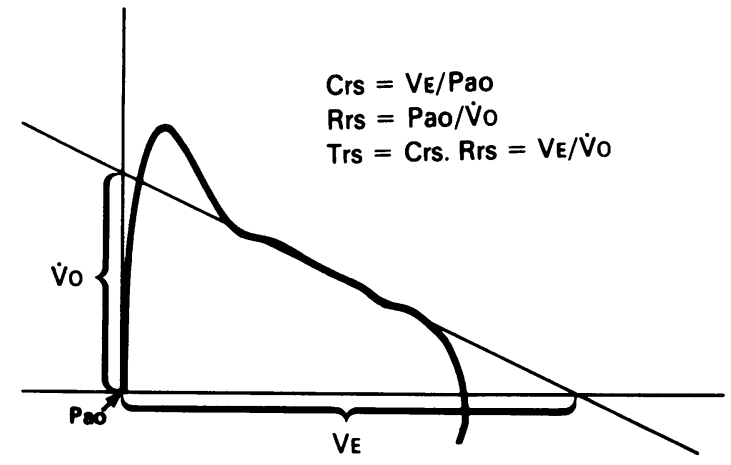

Fig 1 Passive expiratory flow-volume curve from one infant. The slope is extrapolated to the flow (VO) and volume (VE) axes. Calculations are described in the text.

ventilating bag, which bypassed the pneumotachograph. Constant pressure tracings during isovolume ventilation and pressure plateau during occlusion excluded any appreciable leak around the endotracheal tube or in the measuring device. Because of the prolonged expiration to zero flow in these infants with severe airways obstruction, oxygen enriched air was supplied before each measurement and skin colour and heart rate were constantly monitored. Occlusion was performed at several different lung volumes, but before each occlusion the lungs were inflated to total lung capacity to standardise preceding pressure-volume relationships. ${ }^{11}$ PEFV curves were recorded after removal of the occlusion and the expiration was allowed to continue until there had been no expiratory flow for 3 to 4 seconds. The PEFV curves obtained in an individual patient initiated from different lung volumes were compared by assuming that after each passive expiration the same absolute end expiratory volume was achieved. We found that the PEFV curves of an individual infant were superimposed, except for the transient rise in flow immediately after occlusion. The transient flow recorded immediately after removal of the occlusion was ignored and Trs, Rrs, and Crs were calculated for each lung volume at which the occlusion was performed.

\section{Forced expiratory flow manoeuvre}

Partial forced expiratory flow-volume (FEFV) curves and maximum flow at functional residual capacity (VंmaxFRC) were obtained by a modified version of the rapid compression technique. ${ }^{8}$ The chest and abdomen were compressed by rapid inflation of a plastic cuff enclosed in a nylon mesh jacket (fig 2). The cuff covered the chest and abdomen and its position did not change throughout the examination. The outer nylon jacket minimised pressure dissipation away from the chest. With this device about $70 \%$ of the cuff pressure was transmitted to the alveoli and airways as 


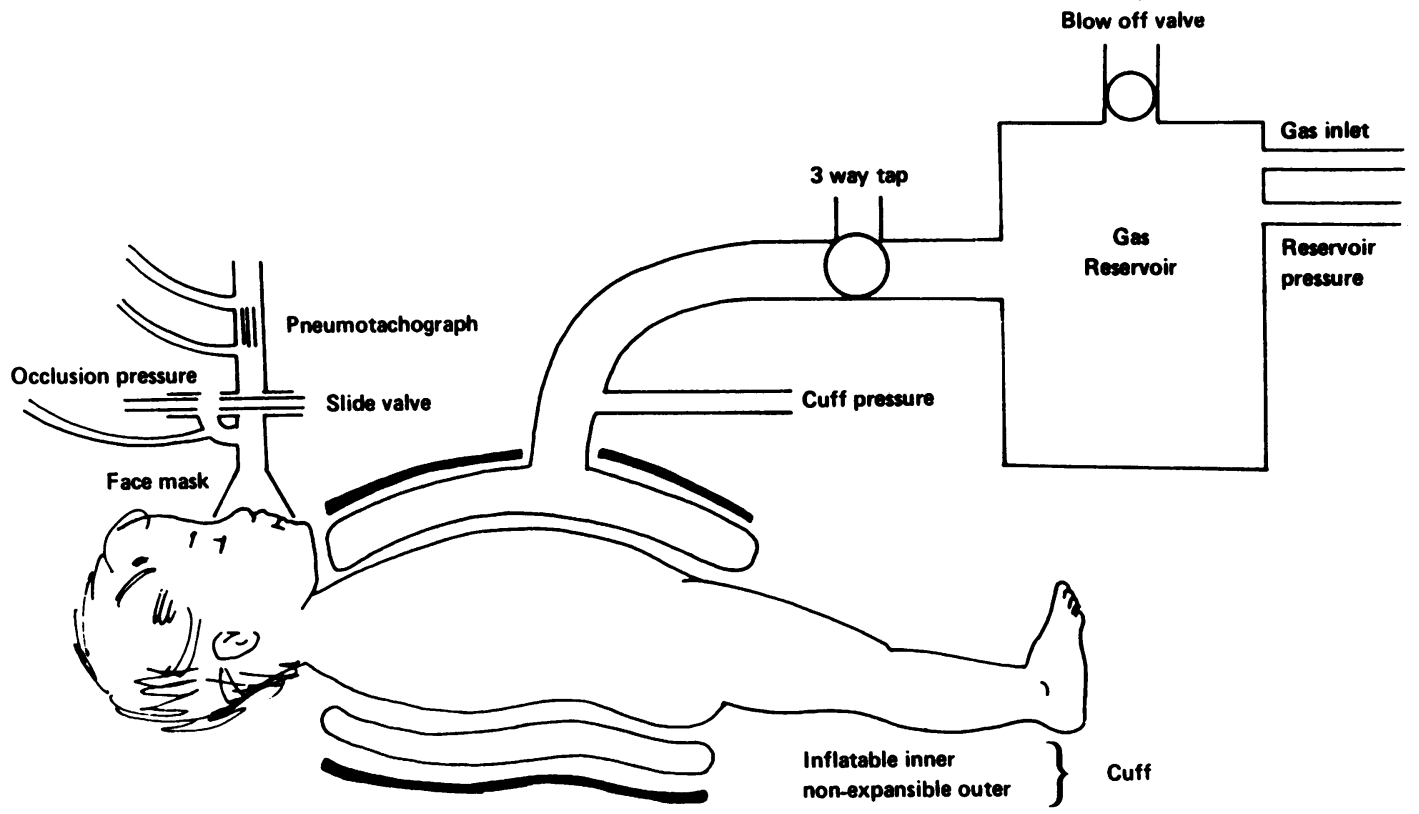

Fig 2 Apparatus for generating partial forced expiratory flow-volume curves.

measured by the increase in mouth pressure during occlusion. ${ }^{12}$ Virtually instantaneous inflation of the cuff was achieved by decompressing a gas storage drum through a wide bore connecting tube. ${ }^{12}$ Pressure within the drum was carefully regulated by a water filled manometer and a safety blow off valve. FEFV curves were obtained by progressively and carefully increasing chest compression until the shape of the FEFV curve and VmaxFRC were constant and did not increase with further increases in chest compression pressure. Care was taken to avoid a negative "effort" effect when increasing pressure resulted in submaximum flow. With this occurred the cuff pressure was reduced until true maximum flow was again achieved. Final selection of curves with maximum flow for analysis was made when the raw signals were played back from the tape on to an oscilloscope.

\section{Thoracic gas volume}

Thoracic gas volume (TGV) was measured at end expiration in the constant volume body plethysmograph by the classic method of DuBois. As the infant attempted three or four spontaneous breaths after airways occlusion mouth pressure and box pressure were plotted on the $x$ and $y$ axes of a storage oscilloscope and TGV was calculated by applying Boyle's law. ${ }^{2}$ Calculations were corrected for dead space and adjusted for the difference between the measured and previously stable FRC. TGV at end inspiration was also measured in 10 babies during the first study, though unless otherwise stated TGV refers to end expiratory TGV.

DATA ANALYSIS

Calculations were made after slowly playing back the taped records on to the oscilloscope and XY plotter (National VP 6123A). Each final measurement was a mean of at least five individual measurements made from technically satisfactory curves except in the case of $\dot{V}$ maxFRC, where the highest value achieved was taken. The results were compared with normal data obtained by the same investigators from six healthy infants studied longitudinally on four occasions when aged 4-55 weeks. Prediction values based on height were derived from that study. ${ }^{8}$

The Wilcoxon signed rank and Mann-Whitney tests were used to compare the data from the infants with bronchiolitis and to compare these with the data from the normal infants. The $\mathbf{0 . 0 5}$ level of probability was assumed to be significant.

\section{Results}

ACUTE STUDIES

Mean end expiratory TGV for the 14 infants was increased (table 1), though five infants had an end expiratory TGV within the normal range (less than 30 $\mathrm{ml} / \mathrm{kg}$ ). Mean (SEM) end inspiratory TGV minus tidal 
Table 1 Pulmonary function measurements (mean (SEM)) in 14 infants with acute viral bronchiolitis compared with measurements in six healthy infants

\begin{tabular}{|c|c|c|c|}
\hline & $\begin{array}{l}\text { Bronchiolitis } \\
\text { acute phase } \\
(n=14)\end{array}$ & $\begin{array}{l}\text { Normal } \\
\text { infants } \\
(n=6)\end{array}$ & $\begin{array}{l}\text { Significance } \\
\text { of difference } \\
\text { between } \\
\text { groups }(p)\end{array}$ \\
\hline $\begin{array}{l}\text { Age (w) } \\
\text { Weight }(\mathrm{kg}) \\
\text { Height }^{3}\left(\mathrm{~m}^{3}\right) \\
\text { TGV }(\mathrm{ml}) \\
\text { TGV/kg }(\mathrm{ml} / \mathrm{kg}) \\
\text { VmaxFRC }(\mathrm{ml} / \mathrm{s}) \\
\text { VmaxFRC/TGV } \\
(\mathrm{TGV} / \mathrm{s})\end{array}$ & $\begin{array}{c}20.0(3.4) \\
6.22(0.42) \\
0.25(0.018) \\
228(19) \\
37.6(2.8) \\
94(15) \\
0.406(0.055)\end{array}$ & $\begin{array}{c}19.0(1.8) \\
6.90(0.44) \\
0.27(0.023) \\
177(11) \\
25.8(1.6) \\
284(28) \\
1.594(0.086)\end{array}$ & $\begin{array}{l}\text { NS } \\
\text { NS } \\
\text { NS } \\
<0.05 \\
<0.01 \\
<0.001 \\
<0.0001\end{array}$ \\
\hline $\begin{array}{l}\mathrm{Crs}\left(\mathrm{ml} / \mathrm{cm} \mathrm{H}_{2} \mathrm{O}\right) \\
\mathrm{s} C r s\left(\mathrm{~cm} \mathrm{H} \mathrm{H}_{2} \mathrm{O}^{-1}\right) \\
\operatorname{Rrs}\left(\mathrm{cm} \mathrm{H}_{2} \mathrm{O} \cdot \mathrm{s} \cdot \mathrm{ml}^{-1}\right) \\
\text { sGrs }\left(\mathrm{s}^{-1} \cdot \mathrm{cm} \mathrm{H}_{2} \mathrm{O}^{-1}\right) \\
\operatorname{Trs}\left(\mathrm{s}^{-1}\right)\end{array}$ & $\begin{array}{l}6.84(0.50) \\
0.031(0.002) \\
0.049(0.003) \\
0.099(0.007) \\
0.325(0.021)\end{array}$ & $\begin{array}{l}9.04(0.99) \\
0.051(0.005) \\
0.039(0.003) \\
0.150(0.012) \\
0.359(0.056)\end{array}$ & $\begin{array}{l}\text { NS } \\
<0.01 \\
<0.05 \\
<0.01 \\
\text { NS }\end{array}$ \\
\hline
\end{tabular}

For abbreviations see text.

volume in the 10 babies in whom this measurement was performed was $42(3.5) \mathrm{ml} / \mathrm{kg}$, significantly higher than end expiratory TGV $(37(3.5) \mathrm{ml} / \mathrm{kg}$; $\mathrm{p}<0.05)$. End inspiratory TGV less tidal volume was higher than end expiratory TGV in infants both with and without hyperinflation, though more strikingly in the former.

The passive expiratory flow-volume (PEFV) curve was a straight line in 11 of the 14 spontaneously breathing patients. In the remaining three patients it became curvilinear towards end expiration. Superimposing the forced, passive, and tidal volume curves produced similar lines for the three curves in these patients (fig 3).

Mean Rrs for the 14 infants was significantly increased, whereas mean specific compliance (sCrs) (that is, compliance divided by the lung volume at which it was measured) and mean specific conductance (sGrs) were significantly less than in the normal infants (table 1).

The FEFV curve was convex towards the $x$ axis in 13 of the 14 patients. There was a significant decrease in the mean VmaxFRC and mean VmaxFRC/TGV (table 1). Twelve of the 14 infants had VmaxFRC/ TGV below the $95 \%$ prediction interval (fig 4). The mean compression pressure needed to achieve $\mathrm{V} \max$ in the patients was $35 \mathrm{~cm} \mathrm{H} \mathrm{H}_{2} \mathrm{O}$ compared with $34 \mathrm{~cm}$ $\mathrm{H}_{2} \mathrm{O}$ in normal infants.

The five infants without hyperinflation had changes in $\dot{\mathrm{V} m a x F R C / T G V}$, mean sCrs, and mean sGrs similar to those of the infants with hyperinflation, though mean (SEM) $\mathrm{Ti} / \mathrm{T}$ tot was significantly shorter $(0.382(0.04) v 0.426(0.03) ; p<0.05)$.

In the two paralysed infants with severe bronchiolitis the PEFV curves were also curvilinear. Occlusion at different lung volumes allowed measurement of Rrs and $\mathrm{Crs}$ at varying lung volumes and showed increasing Rrs towards end expiration, followed by decreasing $\mathrm{Crs}$ at slightly lower lung volumes (fig 5).

\section{FOLLOW UP}

Lung function in most infants had improved when retested three to four months later. No PEFV curve remained curvilinear. $\mathrm{TGV} / \mathrm{kg}$ was significantly less than during the acute phase of the illness $(p<0.05)$ and VmaxFRC/TGV was increased ( $<<0.002)$. Trs and $\mathrm{sGrs}$ had not changed significantly, whereas $\mathrm{sCrs}$ had increased $(p<0.05)$. By comparison with a group of healthy infants (table 2), however, significant gas trapping and decreased volume corrected flow rates were still evident.

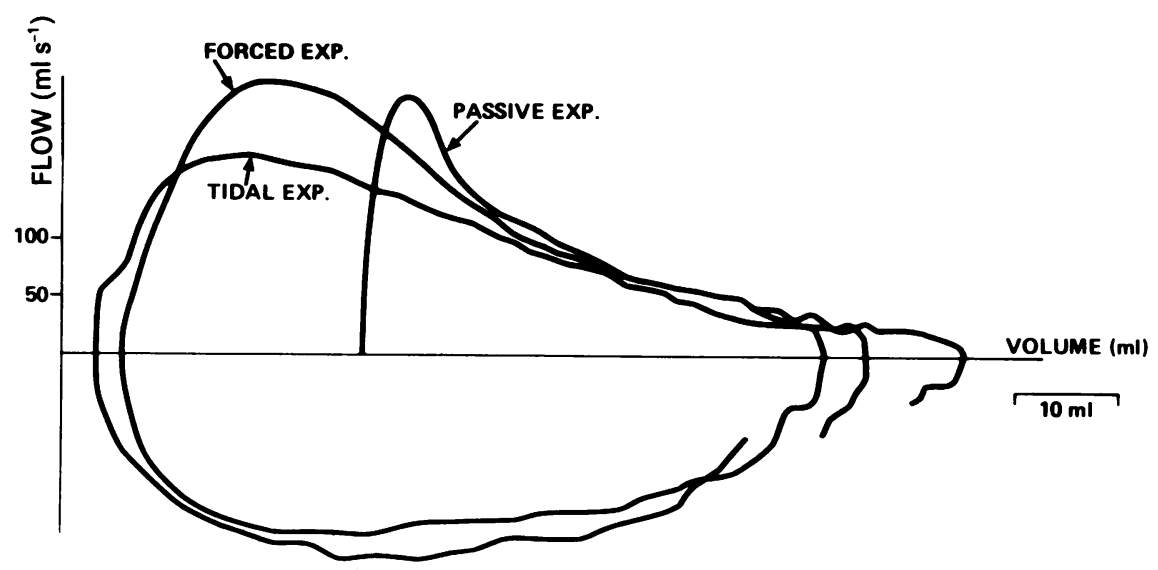

Fig 3 Tidal, passive, and partial forced expiratory flow-volume curves from one infant. The passive curve was superimposed by extrapolating all curves to zero flow on the assumption that this occurs at the same absolute lung volume. Note the expiratory flow limitation in tidal and passive expiratory curves. 


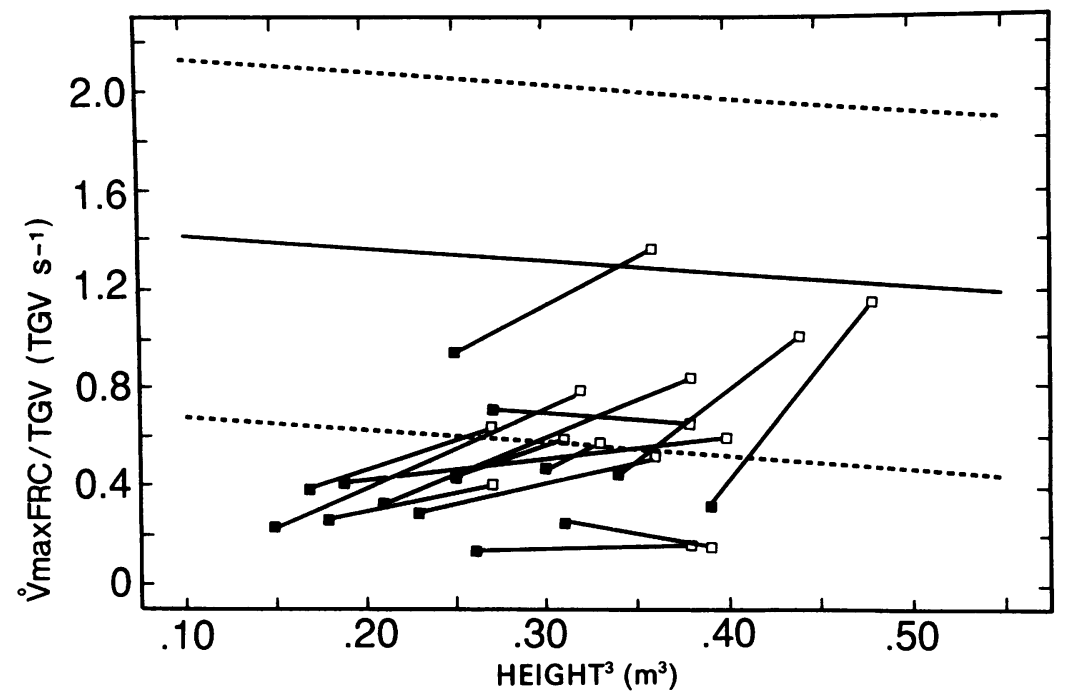

Fig 4 Relation between VmaxFRC/TGV and height during the acute phase (black squares) and recovery phase (white squares). The solid and dashed lines represent the mean and $95 \%$ predicted intervals for normal infants.

\section{Discussion}

This study has shown a pronounced reduction in forced expiratory flow and an increase in respiratory resistance in infants with viral bronchiolitis. Thoracic gas volume at functional residual capacity was substantially increased. Total respiratory compliance did not differ significantly from that of normal babies, though specific compliance was reduced, a reflection of the increase in TGV. The time constant of the respiratory system did not differ from that of normal

Table 2 Pulmonary function measurements (mean (SEM)) in 14 infants who had recovered from acute viral bronchiolitis compared with measurements in six healthy infants

\begin{tabular}{|c|c|c|c|}
\hline & $\begin{array}{l}\text { Bronchiolitis } \\
\text { recovery phase } \\
(n=14)\end{array}$ & $\begin{array}{l}\text { Normal } \\
\text { infants } \\
(n=6)\end{array}$ & $\begin{array}{l}\text { Significance } \\
\text { of difference } \\
\text { between } \\
\text { groups (p) }\end{array}$ \\
\hline $\begin{array}{l}\text { Age (w) } \\
\text { Weight }(\mathrm{kg}) \\
\text { Height }^{3}\left(\mathrm{~m}^{3}\right) \\
\text { TGV }(\mathrm{ml}) \\
\text { TGV/kg }(\mathrm{ml} / \mathrm{kg}) \\
\text { VmaxFRC }(\mathrm{ml} / \mathrm{s}) \\
\text { VmaxFRC/TGV } \\
(\mathrm{TGV} / \mathrm{s})\end{array}$ & $\begin{array}{c}39.0(3.6) \\
8.95(0.39) \\
0.37(0.016) \\
270(19) \\
30.3(1.8) \\
181(27) \\
0.675(0.090)\end{array}$ & $\begin{array}{c}30.5(0.34) \\
8 \cdot 55(0 \cdot 53) \\
0.36(0.016) \\
214(16) \\
25 \cdot 0(1 \cdot 1) \\
262 \cdot(30) \\
1.238(0.118)\end{array}$ & $\begin{array}{l}\text { NS } \\
\text { NS } \\
\text { NS } \\
<0.05 \\
<0.02 \\
\text { NS } \\
<0.02\end{array}$ \\
\hline $\begin{array}{l}\mathrm{Crs}\left(\mathrm{ml} / \mathrm{cm} \mathrm{H}_{2} \mathrm{O}^{-1}\right) \\
\mathrm{sCrs}\left(\mathrm{cm} \mathrm{H} \mathrm{H}_{2} \mathrm{O}^{-1}\right) \\
\operatorname{Rrs}\left(\mathrm{cm} \mathrm{H}_{2} \mathrm{O} \cdot \mathrm{s}^{-1} \mathrm{ml}^{-1}\right) \\
\text { sGrs }\left(\mathrm{s}^{-1} \cdot \mathrm{cm} \mathrm{H}_{2} \mathrm{O}^{-1}\right) \\
\operatorname{Trs}\left(\mathrm{s}^{-1}\right)\end{array}$ & $\begin{array}{c}10.24(0.67) \\
0.039(0.003) \\
0.038(0.003) \\
0.109(0.011) \\
0.388(0.032)\end{array}$ & $\begin{array}{c}10.28(1.09) \\
0.047(0.002) \\
0.035(0.003) \\
0.142(0.015) \\
0.354(0.043)\end{array}$ & $\begin{array}{l}\text { NS } \\
<0.05 \\
\text { NS } \\
\text { NS } \\
\text { NS }\end{array}$ \\
\hline
\end{tabular}

For abbreviations see text. babies. These findings are similar to those reported in studies using oesophageal balloons to measure intrathoracic pressure ${ }^{2}$ and the forced oscillation tech- $\frac{0}{\varnothing}$ nique. ${ }^{13}$ The scientific validity of both these techniques has been questioned. ${ }^{34}$

The techniques used in this study have been developed over recent years. The forced expiratory technique was first applied to newborn infants and papers are now appearing on its use in older infants. ${ }^{61415}$ One potential problem with this method is that the infant may start inspiration before reaching VmaxFRC. The consistency in the forced expiratory flow-volume curves in this study suggests that expiration concluded at a similar point with successive compressions. To obtain reproducible forced expiratory curves, it is important that the compression $\frac{}{3}$ pressure is gradually increased until maximum flow is $\frac{D}{0}$ obtained, as was done in this study. The compression pressure needed to achieve maximum flow in the $\widetilde{\sim}$ babies with bronchiolitis was similar to that in normal infants.

The original studies of the passive technique were $\mathrm{c}$ also undertaken in newborn infants but there are now reports of its use in healthy older infants ${ }^{8}$ and in the evaluation of the efficacy of salbutamol in infants with $\stackrel{\Phi}{\Phi}$ acute viral bronchiolitis. ${ }^{16}$ It relies on the presence of $\stackrel{+}{-}$ the Hering-Breuer reflex and the assumption that after $\frac{0}{-}$ a period of short occlusion the infant passively expires $\overrightarrow{\mathbb{D}}$ to FRC. To exclude active respiratory muscle activity $\frac{?}{\square}$ requires direct measurement of muscle activity, which $\stackrel{\perp}{\AA}$ is difficult in infants. ${ }^{17}$ There may be an initial flow 

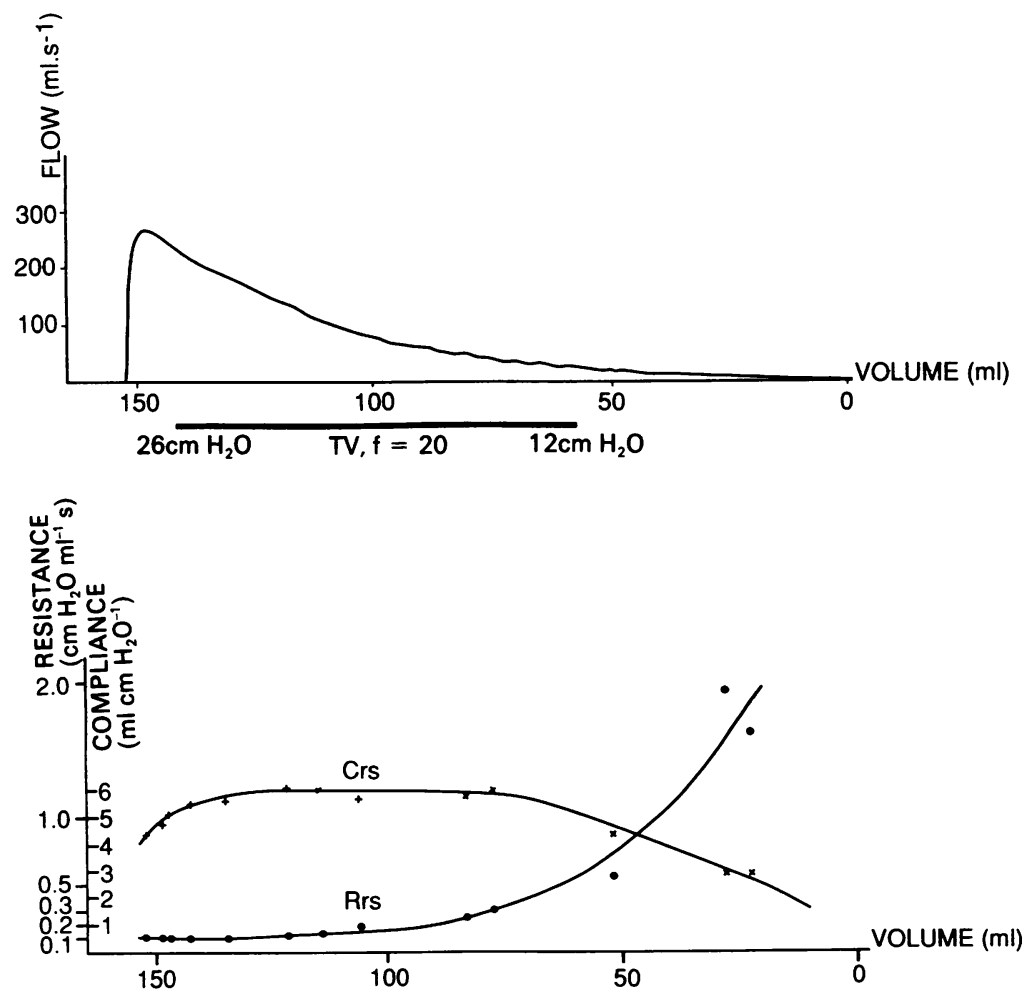

Fig 5 Passive expiration in one of the paralysed and ventilated infants: (a) curvilinear passive expiration (the bar below indicates the volumes of respirator tidal ventilation); (b) calculated Crs and Rrs at the different lung volumes during the passive expiration shown in (a).

transient at the start of passive expiration, reflecting pressurisation of the pneumotachograph. ${ }^{5}$

Thoracic gas volume was measured in the standard way used in this laboratory for 20 years. ${ }^{218}$ One group has recently reported low values of TGV in babies with clinically obvious hyperinflation and offered several possible explanations. ${ }^{19}$ Other laboratories, however, have confirmed hyperinflation in infants with airways obstruction. ${ }^{20}$ The suggestion that differences in calibration may explain the different findings is unlikely as similar methods have been used by the workers who found hyperinflation clinically and physiologically and by those who did not. ${ }^{218}$ Further work is necessary to account for these different findings. Interestingly, end inspiratory TGV minus tidal volume was slightly greater than end expiratory TGV, which is the opposite of previous findings in infants with airways obstruction. ${ }^{21} 22$

The most interesting findings in this study were the curvilinearity of the PEFV curves in three patients, the absence of hyperinflation in five, and the measure- ments made in the two ventilated paralysed infants. In normal infants the PEFV curve is a straight line. ${ }^{823}$ Linearity implies that the product of Crs and Rrs remains constant during passive expiration. ${ }^{24} 25$ The curvilinearity found in the patients with bronchiolitis indicates a changing time constant during expiration, probably due to varying speeds of emptying of areas of lung with different degrees of obstruction. In the paralysed infants there was a rapid rise in resistance with a fall in compliance towards smaller lung volumes, suggesting progressive narrowing and finally closure of small airways with air trapping. Glottic narrowing is suggested as another possible explanation but was excluded in our intubated, paralysed infants; so airways closure is the most likely explanation. Further, with glottic narrowing the initial expiratory resistance usually exceeds end expiratory resistance. ${ }^{26}$ Flattening of the PEFV curve therefore occurs at the beginning rather than towards end expiration. Another possible explanation for the curvilinearity is expiratory muscular activity during 
expiration. ${ }^{24}$ If this occurred early in expiration, an additional increase in mouth pressure should have been observed.

Eleven infants had linear PEFV curves in the presence of increased resistance and hyperinflation. The likely explanation is that tidal breathing was occurring at higher lung volumes where Rrs and Crs did not chānge during expiration. Possibly, however, increasing resistance was balanced by decreasing compliance during expiration so that their product remained constant.

The bar below the curvilinear PEFV curve for the paralysed and ventilated patient shown in figure 5 indicates the volume of ventilator tidal ventilation. It shows that an increase in end expiratory volume allowed breathing at a lower time constant. This leads to increased ventilation without any change in respiratory frequency. This compensation for airways closure may explain why no difference was found in time constants from the passive curve between infants with bronchiolitis and the normal controls. The forced expiratory flow-volume curve showed increased concavity with decreased VmaxFRC in the infants with bronchiolitis. This apparent discrepancy may have arisen because during passive expiration the increase in Rrs is balanced by a decrease in Crs, so that the time constant is unchanged. During the forced manoeuvre, however, the driving pressure for expiration is significantly decreased by the pressure transmitted from the cuff to the pleural space. In the presence of airways disease this pressure leads to narrowing or closure of airways (or both) with a resultant reduction in expiratory flow rates.

The reduction in VmaxFRC is most likely to be due to disease of intrapulmonary airways. It has been suggested that expiratory narrowing of the glottis, "laryngeal braking," may be important in maintaining hyperinflation in asthma, ${ }^{27}$ but if this was a factor in these babies some flattening of the initial portion of the PEFV curve and a much greater rise in Rrs would have been expected.

Five patients with flow limitation, two of whom had curvilinear PEFV curves, did not compensate by hyperinflation. This group appeared to maintain adequate ventilation by spending relatively more time on expiration. The reason for this mode of compensation was not clear. A similar pattern was seen in some patients recovering from acute asthma many years ago. ${ }^{28}$

To analyse the Crs and Rrs when PEFV curves are curvilinear requires interruption during expiration, as in our paralysed infants. This analysis should also be possible in spontaneously breathing infants with the interruptor technique described for animals. ${ }^{28}$ With curvilinear PEFV curves calculation of Crs and Rrs from the initial part of passive expiration, which approximates to a straight line, may be misleading. $\vec{\Rightarrow}$ Extrapolation of the straight part to the volume axis will underestimate the passive expired volume and a falsely low Crs will be calculated. Similarly, the $\frac{\bar{C}}{\bar{C}}$ calculated Rrs will underestimate the change in Rrs $\frac{\text { D }}{\sigma}$ during expiration and so is valid only for the lung $\varrho$ volume at end inspiration.

Thus our studies using recently developed tech- $\overrightarrow{0}$ niques showed substantial reduction in forced expiratory flow in infants with acute viral bronchiolitis $\vec{\omega}$ and suggest that this is due to changes in intrapulmonary airways. There was a much smaller change in Rrs, $\vec{x}$ which is probably more influenced by disease in larger $\stackrel{f}{f}$ airways. Some infants did not compensate for airways $\dot{\varphi}$ narrowing with hyperinflation and they had severe 8 expiratory flow limitation. Further investigation of $O$

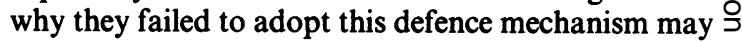
give a better understanding of its origin. Although functional impairment was less at follow up three to four months after the acute bronchiolitis lung function was still significantly different from that of normal $\stackrel{\oplus}{\rightarrow}$ infants.

JS was supported by the Deutsche Forschunggemeinschaft, Federal Republic of Germany.

\section{References}

1 Wohl ME, Stigol LC, Mead J. Resistance of the total respiratory system in healthy infants and infants with bronchiolitis. Pediatrics 1969;43:495-509.

2 Phelan PD, Williams HE, Freeman M. The disturbances of ventilation in acute viral bronchoilitis. Aust Paediatr $J$ 1968;4:96-104.

3 Beardsmore CF, Helms P, Stocks J, Hatch DJ, Silverman M. Improved oesophageal balloon technique for use in infants. J Appl Physiol 1980;49:735-42.

4 Landau LI, Phelan PD. Evaluation of two techniques for measurement of respiratory resistance by forced oscillation. Thorax 1973;28:136-41.

5 Le Souef PN, England SJ, Bryan AC. Passive respiratory mechanics in newborns and children. Am Rev Respir Dis 1984;129:552-6.

6 Adler SM, Wohl MEB. Flow-volume relationship at low lung volumes in healthy term newborn infants. N Pediatrics 1978;61:636-40.

7 Taussig LM, Landau LI, Godfrey S, Arad I. Determi- N nants of forced expiratory flows in newborn infants. $J$ Appl Physiol 1982;53:1220-7.

8 Masters IB, Seidenberg J, Hudson I, Phelan PD, Olinsky A. A longitudinal study of lung mechanics in normal infants. Pediatr Pulmonol 1987;3:3-7.

9 Stocks J, Levy WM, Godfrey S. A new apparatus for the accurate measurement of airways resistance in infancy. J Appl Physiol 1976;43:155-9.

10 Olinsky A, Bryan AC, Bryan MH. A simple method of measuring total respiratory system compliance in newborn infants. S Afr Med J 1976;50:128-30.

11 Mansell AL, Bryan AC, Levison H. Relationship of lung 
recoil to lung volume and maximum expiratory flow in normal children. J Appl Physiol 1977;42:817-23.

12 Le Souef PN, Hughes DM, Landau LI. Effect of compression pressure on forced expiratory flow in infants. J Appl Physiol 1986;61:1639-49.

13 Stokes GM, Milner AD, Hodges IGC, Groggins RC. Lung function abnormalities after acute bronchiolitis. J Pediatr 1981;98:871-4.

14 Silverman M, Prendville A, Green S. Partial expiratory flow-volume curves in infancy: Technical Aspects. Bull Eur Physiopathol Respir 1986;22:257-62.

15 Prendville A, Green A, Silverman M. Paradoxical response to nebulised salbutamol in wheezy infants, assessed by partial expiratory flow volume curves. Thorax 1987;42:86-91.

16 Hughes DM, Le Souef PN, Landau LI. Effects of salbutamol on respiratory mechanics in bronchiolitis. Pediatr Res 1987;22:83-6.

17 Lopes J, Miller NL, Bryan MH, Bryan AC. Importance of inspiratory muscle tone in maintenance of FRC in the newborn. J Appl Physiol 1981;51:830-4.

18 Phelan PD, Williams HE. Ventilatory studies in healthy infants. Pediatr Res 1969;3:425-32.

19 Godfrey S, Beardsmore CS, Maayan C, Bar-Yishay E. Can thoracic gas volume be measured in infants with airways obstruction? Am Rev Respir Dis 1986;133: 245-51.
20 Radford M. Effect of salbutamol in infants with wheezy bronchitis. Arch Dis Child 1975;50:535-8.

21 Helms P. Problems with plethysmographic estimation of lung volume in infants and young children. $J$ Appl Physiol 1982;53:698-702.

22 Beardsmore CS, Stocks J, Silverman M. Problems in the measurement of thoracic gas volume in infancy. $J$ Appl Physiol 1982;52:995-9.

23 Mortola JP, Fisher JT, Smith B, Fox G, Weeks S. Dynamics of breathing in infants. J Appl Physiol 1982; 52:1209-15.

24 Mcllroy MB, Tierney DF, Nadel JA. A new method for measurement of compliance and resistance of lungs and thorax. J Appl Physiol 1963;18:424-7.

25 Zin WA, Pengelly LD, Milic-Emili J. Single-breath method for measurement of respiratory mechanics in anaesthetised animals. J Appl Physiol 1982;52:1266-71.

26 Gottfried SB, Rossi A, Calverley PMA, Zocchi L, MilicEmili J. Interrupter technique for measurement of respiratory mechanics in anesthetized cats. $J$ Appl Physiol 1984;56:681-90.

27 Collett PW, Brancatisano AP, Engel LA. Upper airway dimensions and movements in bronchial asthma. Am Rev Respir Dis 1986;133:1143-9.

28 Woolcock AJ, Read J. Improvement in bronchial asthma not reflected in forced expiratory volume. Lancet 1965 ; ii:1323-5. 